\title{
Prevalence of suicidal attempts in children and adolescents- A tertiary care study.
}

\author{
Manjunathaswamy R. ${ }^{1}$, Ramprasad K.S ${ }^{2}$, Bhargav G.K ${ }^{3}$ \\ ${ }^{l}$ Assistant Professor, Department of Pediatrics, Shivamogga Institute of Medical Sciences, \\ Shivamogga.RGUHS, Karnataka, INDIA) \\ ${ }^{2}$ Assistant Professor, Department of Psychiatry, Shivamogga Institute of Medical Sciences, ShivamoggaRGUHS, \\ Karnataka, INDIA). \\ ${ }^{3}$ Intern, Department of Pediatrics, Shivamogga Institute of Medical Sciences, ShivamoggaRGUHS, Karnataka, \\ INDIA
}

\begin{abstract}
The suicide rates are on a rise in the recent days. The reasons vary from place to place, prevalent social customs and traditions, degree of poverty, urbanization and, gender of the individual. All these factor in varying degree, along with the personality or temperament of the individual results in the outcome-the behaviour. With this background, this study is being undertaken to know the operative factors prevalent in children/adolescents seen at our Institute for attempting suicide.

Aims:1. To study the prevalence of attempt to suicide.2. To identify the factors behind this attempt to suicide Statistical analysis of results was done using percentages and proportions

Results: The study group consisted of 56 children and adolescents, managed at our Institute for attempting suicide. Most of children were in the age group of 2 to 13years and adolescents of 14 to 21 years.

Sex wise distribution of children and adolescentsM: $F=30: 70 M o s t$ subjects affected were from rural area.

Key words: suicidal attempt, adolescents, paediatric, impulsive act, psychosis.
\end{abstract}

\section{Introduction}

The suicide rates are on a rise in the recent days. The reasons vary from place to place, prevalent social customs and traditions, degree of poverty, urbanization and, gender of the individual. All these factor in varying degree, along with the personality or temperament of the individual results in the outcome-the behaviour. With this background, this study is being undertaken to know the operative factors prevalent in children/adolescents seen at our Institute for attempting suicide.

Suicide is a medical and psychological emergency. In the current years the statistical and clinical suicide rates are increased when compared to previous years ${ }^{1,2}$. Suicide is one of the clinical features of severe major depressive disorder. Depression is also being seen in preschool children, school children, adolescents, adult and the elderly. The problem is increasing and is estimated to become the leading cause of morbidity and mortality by another decade or two.

Depression presents as

- Persistent sad and irritable mood

- Loss of interest and pleasure in activities which were previously enjoyable

- Changes in appetite and body weight

- Feeling worthless, hopeless, helpless or inappropriate guilt

- Inability to concentrate

- Thoughts of death or suicide

- Frequent non-specific somatic complaints

- Unusually poor scholastic performance

- Frequent school absence or refusal

- Outbursts of shouting, complaining, irritability or complaining

- Apathy or boredom

- Lack of interest in activities or to be with friends

- Drug abuse

- Withdrawal, social isolation, poor communication

- Sensitivity to rejection or failure

- Temper tantrums, defiance, oppositional or reckless behavior

- Difficulty in maintaining relationships

- Regression-bedwetting ${ }^{4}$ 
Mainly in children and adolescents, Depression occurs due to many factors 1). Biological- heritability 2).Social events 3).Psychological perception by the individual of any given events or situations.

Researchers of the University of Oregon estimate that 28 percent of all adolescents (age 13-19) would have experienced at least one episode of major depression, rate established at 3-7\% from ages 13-15 and 1-2 \% less than 13 years.

In 2001, suicide was the third leading cause of death among 1-24 year olds ${ }^{5,6}, 7 \%$ of adolescents who developed major depression may commit suicide ${ }^{5,}{ }^{6}$. However they also have different presentations as compared to their adult counterparts. When they have stress like experiencing significant loss or having attention, hearing or conduct disorders, they are at a greater risk for developing clinical depression. There is no difference between sexes in childhood. But during adolescence, girls develop depression twice as often as boys. Often there will be strong positive family history of parents or close relatives of the child with major depression 4

Major depressive disorder often has onset in adolescence ${ }^{(1,7)}$ across diverse countries ${ }^{(8,9)}$ with substantial psychological impairments ${ }^{(7,10,11)}$ and risk of suicide. Harrington etal ${ }^{12}$ showed 60 percent of the depressed adolescent group had one or more episode of MDD in adulthood. Pine etal ${ }^{13}$ in the longitudinal community survey found a fourfold increased risk of MDD in adulthood.

Rao etal ${ }^{14}$ used Tanner staging and found a high adult recurrence rate and substantial psychological morbidity in adolescent onset MDD than adult onset MDD

\section{Materials And Methods}

Inclusion Criteria: Cross-sectional study of Paediatric and adolescent population coming to emergency department of Mc. Gann district teaching hospital attached to Shimoga Institute of Medical Sciences, Shivamogga were enrolled for the study over a period of 2 months. Both sexes were included

Exclusion criteria: None. The patients and their caregivers were interviewed after they were medically stable to find out the reasons for their admission to the hospital.

Fig1: Distribution of causes in present study population.

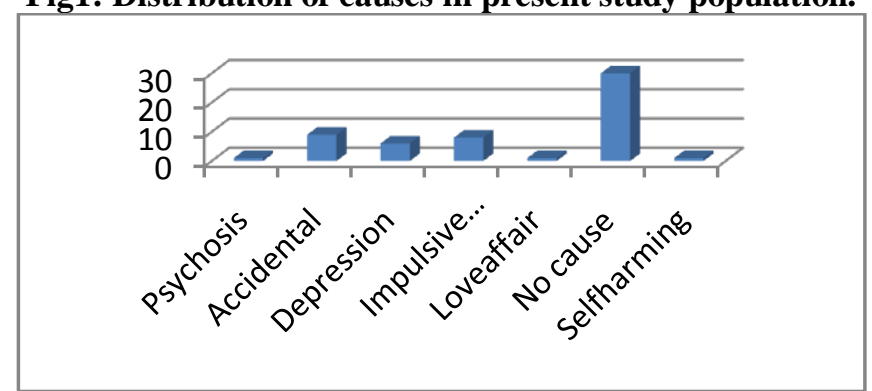

Fig 3:Geographic Population distribution in study.

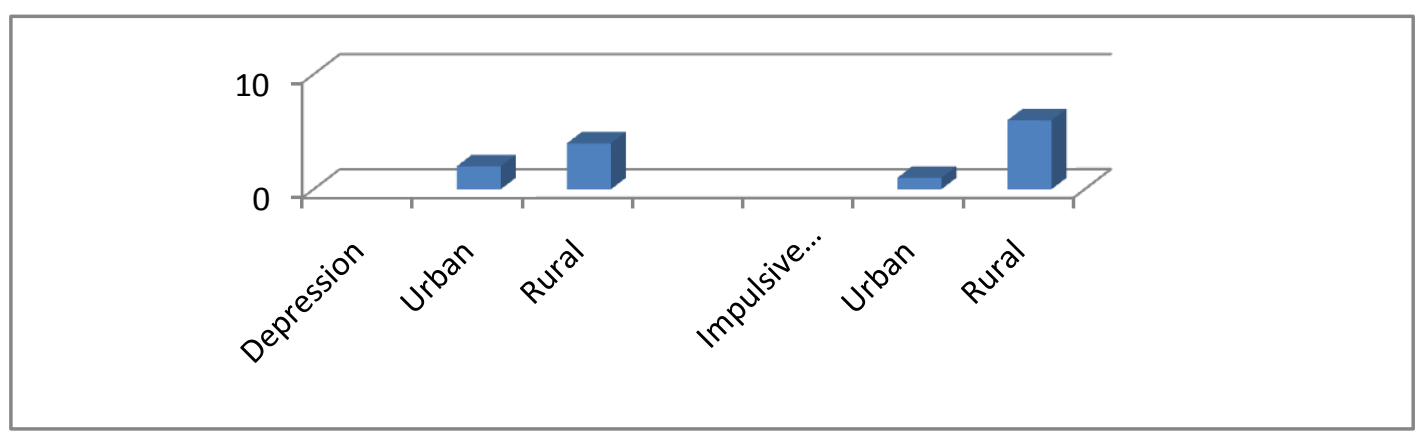

\section{Results}

In our study, we had 56 patients of which 16 were males, 40 were females and most were adolescents. Most no. of children were in the age group of 2 to 13 years (14\%) and adolescents were in the age group of 14 to 21 years $(86 \%)$. The reasons for attempt to end the life varied- Depression, Impulsive act, Psychosis, love affair, self-inflicting injury and no cause found. The rural dwelling population showed high propensity for ending the life. The causes for attempting the suicide act varied with Depression being the second most common cause. No reasons top the cause list. However majority of the suicide attempt revealed no exact cause for varied reasons, to be searched for in further settings. 


\section{Discussion}

The race for possessing, achieving, the inability to reach or to get the wished one leads to disappointment and adding to it the temperament or the personality determines the outcome. The reasons are some known to all like stress at school, peers pressure, parental societal status and others are individualized. This study replicates higher incidence of suicide due to depression in adolescents than in children as seen in Fig3. Adolescent girls outnumber the boys which are also seen in another study ${ }^{3}$.

\section{References}

[1]. Richard Harrington in British Medical Bulletin, 2001:57:47-60

[2]. McClurc GMG. Suicide in children and adolescents in England and Wales 1960-1990. British Journal of psychiatry 1994; 165:5104.

[3]. Ralph E, Depression in children and adolescents: Information for Parents and Educators, c 2004, Association National of School Psychologists, Bethesda. 20814-(301)657-0270.

[4]. Seeley, J., Rohde, P., Lewinsohn, P., \&Clarke, G. (2002). Depression in youth: Epidemiology, identification, and intervention.

[5]. In M.Shinn, H.Walker, and. G.Stoner (Eds.), Interventions for academic and behavior problems II: Preventive and remedial approaches (pp.885-912).Bethesda, MD: National Association of School Psychologists.

[6]. Angold A, Costello EJ, Worthman CM. Puberty and depression: the roles of age, pubertal status and pubertal timing.Psychological Medicine 1998:28:51-61.

[7]. Lewinsohn PM, Rohde P, Seeley JR. Psychological risk factors for future adolesecent suicide attempts. Journal of Consulting Clinical Psychology. 1994; 62:297-305.

[8]. Cross-National Collaborative Group. The changing rate of major depression: cross national comparisons. JAMA.1992; 268:30983105.

[9]. Weissman-MM, Bland R, Canino G.et al. Cross -national epidemiology of major depression and Bipolar disorder, JAMA. 1996:276:293-299.

[10]. Fleming JE, Offord DR. Epidemiology of childhood depressive disorders: a critical Review.571 -580.

[11]. Orvaschel H, Levinsohn PM, Seeley JR. Continuity of psychopathology in a community sample of adolescents. Journal of American Academy of Child Adolescent Psychiatry. 1995; 34:1525-1535.

[12]. Harrington RC, Fudge H, Rutter ML, Pickles A, Hill J. Adult outcomes of childhood and adolescent depression, I: psychiatric status. Archives of General Psychiatry.1990; 47:465-473.

[13]. Pine DS, Cohen P, Gurley D, Brooke J, MaY. The risk for early -adulthood anxiety and depressive disorders in adolescents with anxiety and depressive disorders. Archives of General Psychiatry.1998; 55:56-64.

[14]. Rao U, Ryan ND, Birmaher D. et al. Unipolar depression in adolescents: clinical outcome in adulthood. Journal of American Academy Child and Adolescent Psychiatry. 1995:34:566-577. 